\title{
A Review of Smart Energy Metering System Projects
}

\author{
Folasade M. Dahunsi ${ }^{\text {a, }}$, , Sodiq O. Eniola a, Akinlolu A. Ponnle ${ }^{\text {b }}$, Olaide A. \\ Agbolade $^{\text {b }}$, Charles N. Udekwe ${ }^{\text {b }}$, Adegoke O. Melodi ${ }^{\text {b }}$ \\ ${ }^{a}$ Computer Engineering Department \\ The Federal University of Technology Akure \\ Ondo State, Nigeria \\ ${ }^{b}$ Electrical and Electronics Engineering Department \\ The Federal University of Technology Akure \\ Ondo State, Nigeria
}

\begin{abstract}
The rule of thumb dictates that for any country to have a stable and sufficient power supply, there must be at least a thousand Megawatts of electricity for every one million population. However, many developing countries generate far less than the population demand. Despite not generating enough, enormous electrical power loss, energy theft, and unpaid bills are major problems bedeviling the power distribution companies. A fundamental process in the electricity cycle is energy metering from power generation to distribution and consumption. For decades now, manual (or conventional) energy meters are used to estimate every end-user's energy consumption. But there are lots of setbacks to these meters. These meters were unable to solve the problems of power loss and theft, giving necessity to developing a metering system that will serve as a solution to all issues emanating from the consumer end. The past decade saw many developments of such meters, where all are based on the internet of things (IoT) technology. Such meters are called - by the early developers - a smart energy metering system (SEMS), or simply, a Smart Meter. While there have been several reviews on SEMS, most were found to be based on the instant billing capabilities of SEMS, system development, and the wireless communication protocols of the systems. This review focuses on individual components of SEMS with particular attention to the different types and modes of sensors used for other applications. It analyzes various SEMS designs, microcontrollers, sensors, modules, transducers, communication protocols, data storage accuracy, and maximum power capability. Also discussed are the achievements and weaknesses of the designs, some future research challenges, and open issues in the implementation of SEMS.
\end{abstract}

Keywords: energy, internet of things, microcontrollers, sensors, smart meters.

\section{INTRODUCTION}

Electricity supply is becoming a challenge for most developing nations due to rapid population growth. The economic boom is another critical factor influencing demand surge for electricity, thus making energy conservation and management systems an indispensable element of the energy generation and distribution value chain [1]. The problems related to energy distribution and consumption are often closely related to end-users' perspectives, which can be deliberate or otherwise. Indirectly, consumers contribute to energy wastage by not being mindful of how they use energy in their facilities (e.g., households and factories). Other significant problems of the power sector are unpaid bills and power theft, which are the results of the deliberate actions of consumers. A survey in [2] revealed that the bulk of the total financial loss in the power sector is due to unpaid bills by industries, households, and agroallied establishments. The study identified this as power theft, which is increasingly becoming the primary cause of voltage fluctuation and poor energy distribution in

\footnotetext{
* Corresponding Author.

Email: fmdahunsi@futa.edu.ng

Received: June 12, 2021 ; Revised: July 23, 2021

Accepted: August 10, 2021 ; Published: August 31, 2021

Open access under CC-BY-NC-SA

(C) 2021 PPET - LIPI
}

most countries. Power theft is a crime that results in significant economic loss for Electricity companies [3].

To avoid these losses, monitoring of the power consumption and losses is needed to optimize the utilization of generated power. The billing generated by the energy meter is an essential part of energy distribution. The meter widely in use in developing countries requires an official of the electricity distribution company to take meter readings and calculate the bill of end-users physically. The problem with this system is that it requires significant labor, timeconsuming, and error-prone [4]. Aside from being strenuous and less effective, the conventional meter is not intelligent enough to detect power wastage and theft. Over time, to enhance the efficiency of these meters, many papers have proposed some improvements to conventional energy meters, with the Smart Energy Meter being one [2].

A smart energy metering system (SEMS) is an electric device with an energy meter chip to measure energy consumption and data communication capability using a wireless protocol and peripheral devices for security purposes, data shows, and meter controlling, among several others [5]. Smart meters can inform electrical distribution companies of electrical failures in real-time to facilitate quick repair [6]. They often also include features that make it possible to notify users whenever power consumption exceeds a preset value. Some, such as the one proposed by [5], have 
wireless billing capability to improving cost and time savings. Other features offered by SEMS to customers include the possibility to read real-time rates and pricing policies [7] and provide distribution companies with frequent meter readings [8]. Paraskevakos was proposed the first automatic meter reading system (AMRS) using an advanced technology introduced by Theodore George [9].

SEMS is designed to offer more features when compared to mechanical meters such as self-monitoring, remote sensing, two-way communication, expanded control, and increased consumer choices [10]. These functionalities are all possible with the aid of the rapidly involving technology ecosystem called the internet of things (IoT). The concept of IoT was first introduced in 1999 by Kevin Ashton. The term defined a concept of computers and machines with sensors, which are connected to the internet to report status and accept control commands [11]. IoT concept enables us to connect the normal day-to-day devices over the internet, whereby the devices connected through the IoT space can be accessed and analyzed remotely. Its concept provides the basic infrastructure and opportunities to connect the physical world and computer-based systems [12]. This paper discusses some SEMS designs, their constituents, their achievements, and their weaknesses. Suggestions for improvements are also provided at the end of the paper.

\section{A. Bibliometric Analysis}

To provide an overview of the existing review works on SEMS designs and developments, a bibliometric analysis was conducted on the 9th of July, 2020, as shown in Figure 1, using four acknowledged database platforms of Scielo, SpringerLink, ScienceDirect, and Emerald Insight. Figure 1 shows the distribution of review papers found in each of the 4 databases between 2010 and 2020. The highest numbers of review papers were found on SpringerLink and ScienceDirect. Figure 2 shows the yearly progressive chart of selected papers between 2010 and 2020 .

\section{B. Related Review Articles}

Many review articles on SEMS were carefully studied; however, most of the articles are either not upto-date (even probably outdated) or only treating a part of the constituents of SEMS, and such, not as

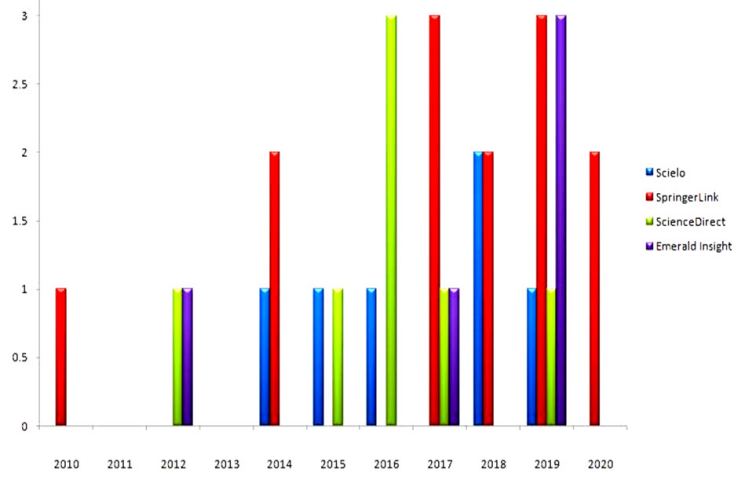

Figure 1. Database Distribution of Selected Articles

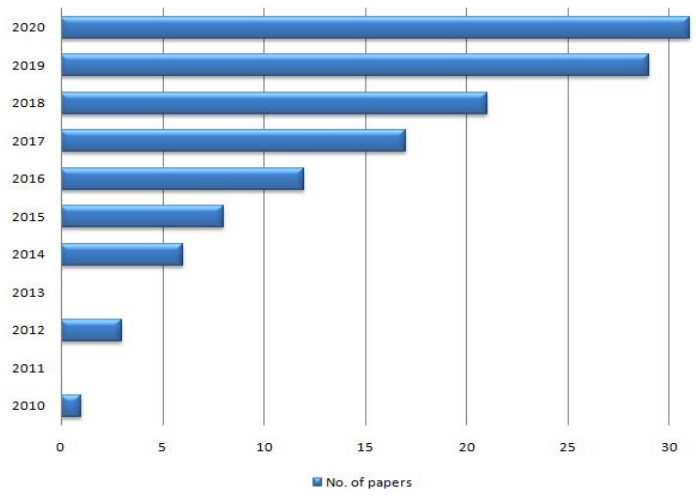

Figure 2. Yearly Progressive Chart of Selected Articles

comprehensive as this paper. The review in [13] discussed the traditional energy meters, their working principles, and the evolution of the SEMS with its advanced functionalities. The consumer behavior towards SEMS and their advantages over the conventional (manual) electromechanical meters were discussed by [14]. [15] proposed a working model of SEMS and the various parts of the SEMS circuitry like digital display, wireless communication protocols, and data logging, among others. [16] discussed the different wireless communication systems used in SEMS, including the WiMAX, ZigBee, and GSM modules. [17] proposed the development of an Automatic Meter Reading System which featured the smart meter working with PIC, GSM/GPRS module, and a dotNET-based frontend web page which served as the interface for the system. While [18], [19] emphasizes the preference of GSM and Wi-Fi modules for SMS and data transfer to the cloud, respectively. An application-oriented review of smart meter data analytics that follows the three stages of analytics and the techniques and methodologies adopted to address its application was discussed by [20]. [21] proposed the use of a MicroSD shield or MicroSD slot-equipped modules for data logging and storage. The implementation of energy theft detection in real-time and two-way communication (meter to cloud and cloud to the meter) with the adoption of IoT protocols was developed by [22]. A summary of related works on SEMS is given in Table 1. The table reveals the focus of several review papers on SEMS. A detailed analysis of these reviews shows that little emphasis was placed on the details and operations of different sensors and actuators used in SEMS applications. In this review, we focus on individual components of SEMS with particular attention to the different types and modes of sensors used.

The organization of this review paper is as follows: Section II presents the concepts and features of the Smart Energy Metering System. The methodology employed during the research selection is presented in Section III. Section IV outlines the necessary constituent components of the SEMS and the various designs employed in each of the designs. Technical comparison of the various components is also presented in Section IV. Section V presents a brief discussion and comparison as well as the response to the research questions. The last section concludes the paper. 
TABLE 1

RELATED REVIEW PAPERS

\begin{tabular}{|c|c|c|c|}
\hline Paper & Review Focus & $\begin{array}{c}\text { Publication } \\
\text { Year }\end{array}$ & $\begin{array}{c}\text { Years } \\
\text { Covered }\end{array}$ \\
\hline$[15]$ & SEMS Circuitry & 2018 & Up till 2017 \\
\hline$[23]$ & $\begin{array}{c}\text { Advancements in SEMS } \\
\text { adoption }\end{array}$ & 2014 & $2008-2012$ \\
\hline$[13]$ & $\begin{array}{c}\text { SEMS development and } \\
\text { application }\end{array}$ & 2018 & - \\
\hline$[16]$ & $\begin{array}{c}\text { SEMS Wireless } \\
\text { Communication }\end{array}$ & 2015 & Up till 2014 \\
\hline$[20]$ & $\begin{array}{c}\text { Smart Meter Data } \\
\text { Analytics }\end{array}$ & 2018 & $2010-2017$ \\
\hline$[22]$ & $\begin{array}{c}\text { SEMS monitoring \& } \\
\text { controlling system }\end{array}$ & 2019 & Up till 2018 \\
\hline$[18]$ & SEMS IoT with GSM & 2019 & - \\
\hline$[19]$ & SEMS IoT & 2019 & - \\
\hline$[17]$ & $\begin{array}{c}\text { Auto Meter reading \& } \\
\text { Instant Billing }\end{array}$ & 2015 & Up till 2015 \\
\hline$[21]$ & SEMS development & 2017 & - \\
\hline & \multicolumn{2}{|c|}{} \\
\hline
\end{tabular}

\section{SEMS: CONCEPTS AND FEATURE}

SEMS is the improved version of the conventional analog electricity meters used in $95 \%$ of the places throughout the world [18]. The concept of SEMS started gaining popularity back in 2008 , though it has been in existence for a few years earlier. SEMS features advanced functionalities that include real-time power status feedback, remote billing, remote communication, energy theft detection, power data logging and storage, and cloud (web-based) monitoring. Table 2 summarizes the advantages of SEMS over conventional energy meters. Figure 3 shows the standard block diagram on which most of the SEMS designs are developed. Typically, SEMS designs consist of a microcontroller that functions as the brain of the system. The design will also most certainly be comprised of sensors for current and voltage measurement. SEMS design will also incorporate either a GSM or Wi-Fi module for wireless connectivity to cloud or service provider, a relay, and several other features to enhance performance and functionality.

\section{Methodology}

The procedure employed during this research is Kitchenham's systematic literature review methodology or procedure [24] which includes research question formulation, search processes, inclusion and exclusion

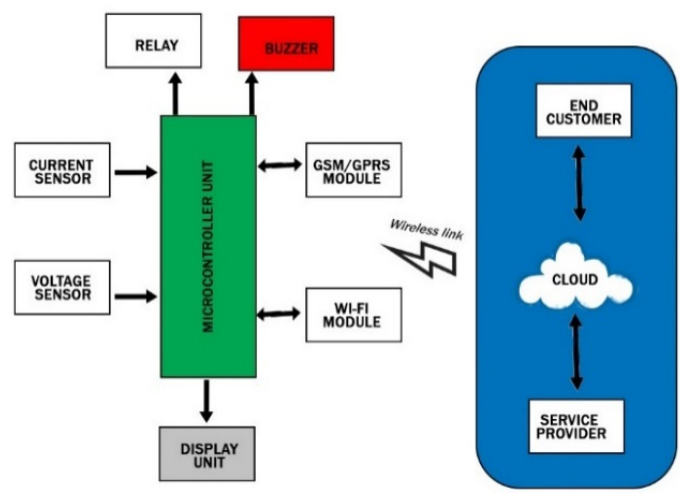

Figure 3. Block Diagram of a Standard Smart Energy Metering System
TABLE 2

COMPARISON BETWEEN SEMS AND THE CONVENTIONAL ENERGY METERS

\begin{tabular}{|c|c|c|}
\hline Features & $\begin{array}{c}\text { Conventional } \\
\text { Meters }\end{array}$ & SEMS \\
\hline $\begin{array}{c}\text { Measurement technology } \\
\text { (Of energy used) }\end{array}$ & $\begin{array}{c}\text { Magnetic } \\
\text { Coupling }\end{array}$ & $\begin{array}{c}\text { Current and Voltage } \\
\text { Transducers }\end{array}$ \\
\hline Energy Supply Control & No & Relay \\
\hline Feedback/Data Collection & Manual & $\begin{array}{c}\text { Automated (Cloud and } \\
\text { SMS) }\end{array}$ \\
\hline User Interface & GBD and LCD & $\begin{array}{c}\text { LCD, LED, OLED, } \\
\text { Mobile App }\end{array}$ \\
\hline Remote Accessibility & No & $\begin{array}{c}\text { Cloud (Web and } \\
\text { Mobile app) }\end{array}$ \\
\hline $\begin{array}{c}\text { Real-time Communication } \\
\text { protocol }\end{array}$ & No & Wireless \\
\hline $\begin{array}{c}\text { Power limit } \\
\text { monitoring/Trip off }\end{array}$ & No & Relay Control \\
\hline $\begin{array}{c}\text { By-pass detection ability/ } \\
\text { Energy theft detection }\end{array}$ & No & Yes \\
\hline
\end{tabular}

processes, data collection, and data analysis. The formulation of relevant research questions is an essential process when conducting research. The questions, which entail the basis and focus of the study, are inferred from the analysis of the different issues expressed in the various review works. This comprehensive review paper presents inclusive answers to the following research's analytical questions (AQ) regarding the focus of this research:

AQ 1. What constituent(s) is/are common in all SEMS designs? What makes up the SEMS?

AQ 2. On which platforms are the SEMS mainly based?

AQ 3. What accounts for the differences in the various SEMS designs?

AQ 4. What are the future directions and open perspectives in SEMS designs?

The search was achieved by systematically searching through 4 different citation databases and relevant digital libraries: Scielo, ScienceDirect, SpringerLink, and Emerald Insight. Putting into consideration the synonyms and other alternatives of the key essential components used in the nomenclature of SEMS designs, the keywords combined to formulate the search query that generated the results are the following: (("Smart" OR "Arduino-based" OR "Wireless" OR "IoTbased") AND ("energy" OR "power") AND ("meter" OR "metering system")). For the exclusion criteria, papers that were not written in English or published before 2010 were excluded. Also, papers that do not draw their review's main point to a concrete conclusion or are not clear enough were excluded.

Related and relevant papers published in English from January 2010 to June 2020 were considered and included in this study for the inclusion criteria. After the refinement, data was collected from the selected papers and analyzed, after which the formulated analytical questions are used to classify and categorize the analyzed data in Section 3.

\section{Smart Energy Metering SyStems Design AND DEVELOPMENT}

A typical SEMS design is made up of several constituent components, among which are the voltage sensors or transducers, current sensors/transducers, microcontrollers, buzzers, relays, GSM modules, Wi-Fi 
modules, data logger shields, and display units. Also, most of the systems incorporate cloud technologies in the form of a web or mobile app. Some use SMS, while others use both approaches for remote real-time feedback.

Over the last decade, many SEMSs have been designed and developed by various researchers and developers worldwide. This saw many applications and implementations with different specifications and limitations. These components have different accuracies and precision levels. They also have different input and output limits and reactions to varying conditions, making each suitable for various applications.

This section discusses the technical specification of these sensors and modules and their merits and demerits in their applications in Smart Energy Metering Systems in SEMS.

\section{A. Current Sensors Used in SEMS}

Many current transducers are used in sensing and monitoring the amount of current being used, and they all possess different technical characteristics and limitations. Some are more suitable for home applications, while some are great for industrial applications. Most current sensors used for SEMS applications employ either the inductive technology or Hall Effect for current measurement. The two methods rely on similar principles depending on whether $\mathrm{AC}$ or DC is measured. The principle is based on the fact that when current flows through a conductor, a magnetic field is generated which is easily picked up by sensors and converted into a voltage. The inductive technology is popular with AC sensors and has the major advantage of being minimally invasive. Similar advantages are obtainable with sensors that use Hall Effect, usually for DC measurement.

Popular current sensors include the ACS712 Current Transducer, CR3110-3000, SCT 013-000 Models, LTS 15-NP Current Transducer, LA 55, and the FHS40P/SP600 Current Transducer.

The AC712 is a current sensing module that works on the principle of the Hall Effect. This sensor can measure both $\mathrm{AC}$ and $\mathrm{DC}$, and it provides isolation between the load and the Microcontroller (measuring) unit. With a maximum measurable current of $20 \mathrm{~A}$ and maximum temperature tolerance of just 10 degrees over room temperature, the application area for this sensor is limited to small-scale domestic applications. It, however, has a decent accuracy with an offset range between $0.1 \%$ and $1 \%$, thus making it very reliable. Authors such as [3], [12], [22], [25]-[29], all used the ACS712 in their research. Table 3 presents some characteristics of selected current sensors.

The LTS 15-NP and LA-55 P are two other current sensors with similar characteristics to the AC712. The LTS 15-NP has a slightly lower current tolerance of $15 \mathrm{~A}$. They both have a closed-loop current sensing transformer. With an offset of only $0.2 \%$, the LTS $15-\mathrm{NP}$ is considered one of the most accurate and suitable sensors for speed drives and motors applications because of its fast response time of fewer than 400 nanoseconds.

The LTS 15-NP sensor was used by [30], while [31] opted for the LA 55-P current sensors with good
TABLE 3

CHARACTERISTIC OF SOME CURRENT SENSORS/TRANSDUCERS USED IN SEMS

\begin{tabular}{|c|c|c|c|c|}
\hline $\begin{array}{c}\text { Sensor } \\
\text { Name }\end{array}$ & Manufacturer & $\begin{array}{c}\text { Working } \\
\text { Principle }\end{array}$ & Accuracy & $\begin{array}{c}\text { Max. Input } \\
\text { Current }\end{array}$ \\
\hline ACS712 & Allegro & Hall-Effect & $0.1-1.0 \%$ & $20 \mathrm{~A}$ \\
\hline $\begin{array}{c}\text { CR3110- } \\
3000\end{array}$ & CR Magnetics & $\begin{array}{c}\text { Split-Core } \\
\text { Current } \\
\text { Transformer }\end{array}$ & $1.5-2.0 \%$ & $75 \mathrm{~A}$ \\
\hline $\begin{array}{c}\text { SCT 013- } \\
000\end{array}$ & YHDC & $\begin{array}{c}\text { Split-Core } \\
\text { Current } \\
\text { Transformer }\end{array}$ & $1.0-2.0 \%$ & $100 \mathrm{~A}$ \\
\hline LTS 15-NP & LEM & Hall-Effect & $0.2 \%$ & $15 \mathrm{~A}$ \\
\hline LA 55-P & LEM & Hall-Effect & $0.9 \%$ & $50 \mathrm{~A}$ \\
\hline $\begin{array}{c}\text { FHS- } \\
\text { 40P/SP600 }\end{array}$ & MiniSens & Hall-Effect & $1.0-2.0 \%$ & $100 \mathrm{~A}$ \\
\hline
\end{tabular}

realization. The major let-off of these sensors is their relatively high cost when compared to the AC712. The CR3110-3000 and SCT 013-000 current transducer are high current measurement sensors that utilize a split-core current transformer. The CR3110 has a high secondary turn which develops signals up to $10.0 \mathrm{~V}$ AC across the burden resistor. [32] used this sensor to measure the current consumed by the various appliances and not the load used by the building.

This sensor takes up to 75A maximum input current, making it suitable for industrial applications. At an offset between 1.5 and $2.0 \%$, its accuracy is high but expensive and not very compact in size and weight.

[1], [33]-[35], all opted for the SCT 013-0XX models over the CR3110-3000 sensor because it can handle up to $100 \mathrm{~A}$ input current. Other models of this sensor handle lesser current with the SCT 013-005 model at $5 \mathrm{~A}$ at the least. At $100 \mathrm{~A}$, this sensor is the most suitable for industrial applications. It has high accuracy with an offset of $1.0-2.0 \%$ with a precision of 0.4 . It is small, well priced, and used for most SEMS designs.

The FHS-40P/SP600 is a unique current transducer in that there is an open-loop surface mounted technology (SMT) integrated circuit (IC) Current Transducer that operates on the principle of Hall Effect. It is programmable and suitable for the electronic measurement of AC, DC, pulsed current, or a mixture of all. This programmable transducer can take up to $100 \mathrm{~A}$ maximum input current with acceptable accuracy and compact design. It has low heat resistance, and the IC is socket mounted and can be used only by experts. [7] employed this IC transducer to measure the current usage with noticeable results.

\section{B. Voltage Sensors Used in SEMS}

Voltage sensors operate by detecting magnetic fields, electromagnetic fields, or contact voltage. They are generally classified as either restive type or capacitive type. The resistive type includes a bridge circuit and a voltage divider. One of the resistors in the bridge circuit is used as a voltage detector device. The differential in voltages across these resistors can be amplified and measured to give accurate voltage measurements. The capacitor type sensor relies on the capacitance across two conductors separated with an insulator or dielectric for voltage estimates. There are also several variants and multiple derivations of these sensors. 
The prominent voltage sensors include the ZMPT101B, a small-size Current-type Voltage Transformer. The LV 25-P Voltage Transducer is a closed-loop current-type voltage transducer that uses the principle of Hall Effect, among others. Many designs also used a simple Step-down transformer (240V:9V and 240V:6V mostly) as their voltage sensor, though rectification (AC to DC) is essential in such cases. One of the most popular voltage sensors is the ZMPT101B sensor. It is a small and accurate Current-type Voltage Transformer designed for voltage and power measurement. [33], [29], [32], [34], [35] made SEMS designs using the ZMPT101B sensor for voltage measurement.

The ZMPT101B Voltage Transducer measures in millivolts $(\mathrm{mV})$, thereby giving it $98 \%$ precision. It has an operating voltage of $0-1000 \mathrm{~V}$, compact, and is relatively well priced. A major challenge is its low heat resistance. Table 4 presents some characteristics of selected current sensors.

The LV 25-P voltage transducer is a Current-type voltage transducer that operates on the principle of Hall Effect. It can measure up to $250 \mathrm{~V}$ AC, therefore unsuitable for industrial applications. It has high accuracy with an offset of $0.95 \%$ and an optimized response time and current overload capabilities. It is also very affordable.

This sensor was one of the sensors used by [31] in their research. Step down transformer-based sensor is also common in literature. $6 \mathrm{~V}$ and $9 \mathrm{~V}$ transformers are the commonest. The sensor circuitry often includes a rectifier and voltage divider to ensure compatibility with microcontrollers. The circuit requires many calculations to avoid errors in computations, [36] proposed a voltage level shifter to aid this. If the calculations are carried out correctly, it is the most accurate voltage sensing method. It is cheaper than every other transducer but requires exclusive calculations, which may lead to significant errors if not done correctly. Besides, it cannot handle beyond $240 \mathrm{~V}$ AC which is the threshold of most stepdown transformers, therefore rendering it unsuitable for industrial application.

\section{Output and Communication Processes in SEMS}

Smart energy meter systems require a display or interface for easy user interaction. These interfaces may either be hardware like LCDs and TFTs mounted on the device or through software platforms like SMS and Web App/Server. Platforms like SMS and Web App/Server require special modules and shields for wireless

TABLE 4

Characteristic of SOME Voltage Sensors/TransDucers USED IN SEMS

\begin{tabular}{|c|c|c|c|c|}
\hline $\begin{array}{c}\text { Sensor } \\
\text { Name }\end{array}$ & Manufacturer & $\begin{array}{c}\text { Working } \\
\text { Principle }\end{array}$ & Accuracy & $\begin{array}{c}\text { Max. } \\
\text { Input } \\
\text { Voltage }\end{array}$ \\
\hline ZMPT101B & $\begin{array}{c}\text { Qingxian Zeming } \\
\text { Langxi Electronic }\end{array}$ & $\begin{array}{c}\text { Current-type } \\
\text { Voltage } \\
\text { Transformer }\end{array}$ & $\begin{array}{c}98 \% \\
(1-2 \%)\end{array}$ & $1000 \mathrm{~V}$ \\
\hline LV 25-P & LEM & Hall-Effect & $\begin{array}{c}98 \% \\
(1-2 \%)\end{array}$ & $250 \mathrm{~V}$ \\
\hline $\begin{array}{c}\text { Step-down } \\
\text { Transformer }\end{array}$ & --- & Induction & --- & $240 \mathrm{~V}$ \\
\hline
\end{tabular}

communication. The displays mounted on the device are for local monitoring by the household owners. The software means are for remote monitoring, visualization, and remote access and control for both the household owners (end consumers) and the Power Service Provider. Among the widely used displays are the liquid crystal displays (LCD), a low-cost, small-size display [3], [7], [12], [25]-[28], [37] and TFT (or OLED) displays, a colorful and sometimes, touch-sensitive display [29], [3]. Table 5 shows common features of the common displays. LCD is more widely used because they are cheaper and more easily accessible.

\section{Wireless Communication and Internet Connectivity Devices in SEMS}

Smart energy metering systems require communication capability to function optimally. One of the most commonly used communication modules is the Simcom SIM800L module. The module is a miniature GSM/GPRS module that can be integrated into a significant number of IoT and related projects. It supports quad-band GSM/GPRS network, making it relevant and functional anywhere in the world. It can also be used to accomplish almost anything a standard cell phone can; short messaging service (SMS), make or receive phone calls, internet connectivity through GPRS, TCP/IP, among others. SEMS designs that make use of this module to transmit data recorded by the sensors or receive instruction from the service centre or household owner at any point in time are the following: [7], [25], [28], [35], [37]. Low cost is a significant advantage of this module, but at burst current requirement of about $2 \mathrm{~A}$, it is not the most power-efficient communication module.

Arduino Ethernet shield [1], [27] and Wi-Fi shield [32]-[34] are two commonly used communication modules mainly because of their low power consumption. The major drawback of these shields is their restriction to the Arduino platform.

Other communication module popular with SEMS application include the NRF24L01 [29], ESP8266 [3], [12], [26], [38], LoRa Semtech SX1276/SX1278 [34] and Zigbee [39]. They all operate on the ISM $2.4 \mathrm{GHz}$ band with the exemption of the SX1276. The NRF24L01 module consumes only $12 \mathrm{~mA}$ at $3.3 \mathrm{~V}$ and has the highest data rate at $2 \mathrm{Mbps}$. However, it is expensive and can only be connected over a network of linked devices and not directly to the internet. The ESP8266 is cheap, compact, and can be used as a standalone module. With a data rate of $2.5 \mathrm{Mbps}$, it remains an important choice for applications that require a Wi-Fi connection. LoRa modules are popular because of their long-range capabilities. The SX1278 is capable of covering the distance in the order of about $10 \mathrm{~km}$. They are the preferred choice for an application designed to cover

TABLE 5 ANALysis of The Two STANDARD DisPlay DEVICES USED IN SEMS

\begin{tabular}{|c|c|c|c|}
\hline Sensor Name & Working Principle & $\begin{array}{c}\text { Operating } \\
\text { Voltage }\end{array}$ & $\begin{array}{c}\text { Operating } \\
\text { Current }\end{array}$ \\
\hline $\begin{array}{c}\text { Liquid Crystal } \\
\text { Display (LCD) }\end{array}$ & $\begin{array}{c}\text { Liquid Crystal } \\
\text { (Passive matrix) }\end{array}$ & $4.7 \mathrm{~V}-5.3 \mathrm{~V}$ & $130 \mathrm{~mA}$ \\
\hline $\begin{array}{c}\text { Thin-Film } \\
\text { Transistor LCD } \\
\text { (TFT LCD) }\end{array}$ & $\begin{array}{c}\text { Thin-Film Transistor } \\
\text { (Active matrix) }\end{array}$ & $5 \mathrm{~V}$ & $450 \mathrm{~mA}$ \\
\hline
\end{tabular}


large distances and are also relatively cheap. The major drawback of the LoRa module is their low data rate and therefore not suitable for applications that require the transmission of heavy files like videos or even highdefinition images. They are also not compatible with all microcontrollers and do not have any onboard storage memory allocation. Table 6 presents some characteristics of wireless modules and shields used in SEMS.

ZigBee is a low-power, low data rate, operating in the ISM radio bands $-2.4 \mathrm{GHz}$. It covers up to a range of $100 \mathrm{~m}$ and consumes very low power. Though small in size and inexpensive, it is not suitable for complex applications and it has no onboard storage device.

\section{E. Microcontroller Units (MCUs) in SEMS}

Microcontrollers are the heart and brain of SEMS. A typical microcontroller unit (MCU) is a small computer unit on a single metal-oxide-semiconductor IC chip. They usually include three major parts: the processor (CPU), the memory, and the input/output (I/O) units on a single chip.

Many microcontrollers are used in various SEMS designs, considering their architecture, flash memory size, operating voltage and current, number of I/O pins, and programming processes. Among the most popular MCUs used in SEMS designs are Arduino Uno, Arduino Due, Arduino Mega, Arduino Nano, Microchip's dsPIC30F3014, Microchip's PIC16F877P, and ATMEL's AT89S52.

One of the most popular microcontrollers is the Arduino, mainly because of its large library and ease of use in an integrated development environment (IDE) that reduces the project prototyping cycle. The Arduino comes in different sizes, shapes, and processing abilities. The Arduino Uno [1]-[3], [26], [28], [35], [37], [40]-[42] and Nano [12], [34], [43] are one of the most popular of the family. They are both 8-bit microcontroller boards based on the ATMega328P with a $16 \mathrm{MHz}$ ceramic resonator. They have an in-circuit analog to digital converter with an onboard programmer making them easy to program. They are power efficient and work with a DC range of 7-20V. The Uno has 14 digital pins and 6 analog pins. Table 7 presents the features of some microcontrollers used to develop SEMS.

The Nano has two additional analog pins, but with a small flash memory of only 32 kilobytes, they are both

TABLE 6

ANALYSIS OF THE VARIOUS WIRELESS MODULES AND SHIELDS USED IN SEMS

\begin{tabular}{|c|c|c|c|c|}
\hline Sensor Name & Manufacturer & $\begin{array}{c}\text { Working } \\
\text { Principle }\end{array}$ & $\begin{array}{c}\text { Operating } \\
\text { Voltage }\end{array}$ & $\begin{array}{c}\text { Operating } \\
\text { Current }\end{array}$ \\
\hline $\begin{array}{c}\text { SIM800L/ } \\
\text { SIM900A }\end{array}$ & SIMCOM & GSM/GPRS & $3.3 \mathrm{~V}$ & $\begin{array}{c}60 \mathrm{uA}- \\
453 \mathrm{~mA}\end{array}$ \\
\hline $\begin{array}{c}\text { Arduino Ethernet } \\
\text { Arduino cc }\end{array}$ & Wi-Fi & $5 \mathrm{~V} / 3.3 \mathrm{~V}$ & $\begin{array}{c}40 \mathrm{~mA} / \\
50 \mathrm{~mA}\end{array}$ \\
\hline $\begin{array}{c}\text { Arduino Wi-Fi } \\
\text { shield }\end{array}$ & Arduino cc & Wi-Fi & $3.3 \mathrm{~V}$ & $40 \mathrm{~mA}$ \\
\hline $\begin{array}{c}\text { NRF24L01 } \\
\text { MCU } 66 / \text { Node }\end{array}$ & LEM & RF & $1.9 \mathrm{~V}-3.6 \mathrm{~V}$ & $13.5 \mathrm{~mA}$ \\
\hline LoRa Module & SemTech & RF & $3.3 \mathrm{~V}$ & $4.2 \mathrm{~mA}$ \\
\hline ZigBee & $\begin{array}{c}\text { ZigBee } \\
\text { Alliance }\end{array}$ & RF & $3.3 \mathrm{~V}$ & $150 \mathrm{~mA}$ \\
\hline
\end{tabular}

TABLE 7

ANALYSIS OF THE VARIOUS MICROCONTROLLERS USED IN SEMS

\begin{tabular}{|c|c|c|c|c|c|}
\hline $\begin{array}{c}\text { Micro- } \\
\text { controller }\end{array}$ & $\begin{array}{c}\text { Flash } \\
\text { Memory }\end{array}$ & $\begin{array}{c}\text { No of I/O } \\
\text { Pins }\end{array}$ & $\begin{array}{c}\text { Commu- } \\
\text { nication } \\
\text { Protocols }\end{array}$ & $\begin{array}{c}\text { Operating } \\
\text { Voltage }\end{array}$ & $\begin{array}{c}\text { Operating } \\
\text { Current }\end{array}$ \\
\hline Arduino Uno & $32 \mathrm{~Kb}$ & $\begin{array}{c}\text { Digital=14 } \\
\text { Analog=6 }\end{array}$ & $\begin{array}{c}\text { UART, } \\
\text { SPI, and } \\
\text { I2C }\end{array}$ & $5 \mathrm{~V}$ & $40 \mathrm{~mA}$ \\
\hline Arduino Due & $512 \mathrm{~Kb}$ & $\begin{array}{c}\text { Digital=44 } \\
\text { Analog=12 }\end{array}$ & $\begin{array}{c}\text { UART, } \\
\text { SPI, and } \\
\text { I2C }\end{array}$ & $5 \mathrm{~V}$ & $50 \mathrm{~mA}$ \\
\hline Arduino Mega & $256 \mathrm{~Kb}$ & $\begin{array}{l}\text { Digital=54 } \\
\text { Analog=16 }\end{array}$ & $\begin{array}{c}\text { UART, } \\
\text { SPI, and } \\
\text { I2C }\end{array}$ & $5 \mathrm{~V}$ & $50 \mathrm{~mA}$ \\
\hline Arduino Nano & $32 \mathrm{~Kb}$ & $\begin{array}{c}\text { Digital=14 } \\
\text { Analog=8 }\end{array}$ & $\begin{array}{c}\text { UART, } \\
\text { SPI, and } \\
\text { I2C }\end{array}$ & $5 \mathrm{~V}$ & $40 \mathrm{~mA}$ \\
\hline dsPIC30F3014 & $8 \mathrm{~Kb}$ & 24 & $\begin{array}{c}\text { USART/ } \\
\text { MSSP }\end{array}$ & $4.5-5.5 \mathrm{~V}$ & $12-40 \mathrm{~mA}$ \\
\hline PIC16F877P & $8 \mathrm{~Kb}$ & 33 & USART & $3.3-5.5 \mathrm{~V}$ & $20-40 \mathrm{~mA}$ \\
\hline AT89S52 & $8 \mathrm{~Kb}$ & 32 & UART & $4.0-5.5 \mathrm{~V}$ & $12-40 \mathrm{~mA}$ \\
\hline
\end{tabular}

unsuitable for complex applications that require extensive programming memory. The Arduino mega [29], [33], [44] is an extended version of the Uno. It is based on the Atmega 2560 processor. It has 54 digital input/output pins, 16 analog inputs, 4 UARTs (hardware serial ports), a $16 \mathrm{MHz}$ crystal oscillator, and $256 \mathrm{~KB}$ of flash memory. The mega is more powerful than the Uno but also more expensive.

The Arduino Due [30], [32] is the least popular of the Arduino family. It is the first Arduino board that is based on 32-bit ARM architecture, rather than the ATMega architecture on which most Arduino boards are based. The Arduino Due has an Atmel SAM3X8E ARM Cortex-M3 microcontroller, which has 54 digital input/output pins of which 12 can provide as PWM outputs, 12 analogue inputs, 4 UARTs (hardware serial ports), an $84 \mathrm{MHz}$ clock, a USB OTG-capable connection, 2 TWI, 2 DAC (digital-to-analog converter), a power jack, an SPI header, a JTAG header, a reset button, and an erase button. It is a lot more powerful than any of the other Arduino families but also the most expensive.

Other commonly used microcontrollers for SEMS application include the dsPIC30F3014 [25], PIC16F877P [4] and the ATMEL AT89S52 [45]. The dsPIC30F3014 is a 16-bit Digital Signal Microcontroller based on the Modified Harvard Architecture and C Compiler Optimized Instruction Set Architecture. It has 256 bytes of memory and up to $40 \mathrm{MHz}$ External Clock Input with a 12-Bit analog-to-digital converter (ADC). The PIC16F877P, as well as the ATMEL AT89S52, are also high-performing 8-bit CMOS Flash Microcontrollers. All three have the advantage of power efficiency, same size, and low cost. They, however, have a small memory and require advanced programming skills.

\section{F. Storage Media in SEMS}

Storage is one of the significant advantages of SEMS over analog meters. The most common storage media found in SEMS designs are the MicroSD Card, Cloud storage, or a combination of the two. An on-board, embedded MicroSD slot can be found in several Data Logging Shields like the Arduino Wireless MicroSD 
Shield, Arduino Ethernet Shield, Arduino Wi-Fi Shield, Cooking-Hacks MicroSD Shield, AdaFruit MicroSD Shield, SparkFun MicroSD Shield, and the Raspberry Pi models.

The research in [43] implemented a smart energy metering system using a microSD card for storage. The major advantages include non-volatility of memory cards, small size, large capacity, affordability, and ease of data retrieval. SD cards for most SEMS are usually employed as the backup because accessing data saved on them requires physical access to the memory card. To overcome this limitation, most SEMSs employ the use of cloud storage.

The study in [35] built a Building Environmental Monitoring System (BEMS) entirely on a cloud storage server. SEMS designs like [3], [12], [26], [42], [46] all used already existing IoT platforms to shorten development time. Popular IoT platforms include ThingSpeak, MQQT, Google Firebase, Cayenne IoT platform, Xively, Carriots IoT platform, and AdaFruit IO platform. The advantages of these systems include roundthe-clock access and large memory capacity. However, uploading and retrieving data saved on the cloud is impossible without an internet connection and an internet-enabled device. Besides, for large-scale deployment, cloud storage requires an extensive annual budget.

Another method was to directly connect a SEMS to a computer system using cables and log the data into an Excel $^{\mathrm{TM}}$ spreadsheet (.csv or .xlsx format) for easy MATLAB or Python analysis [44]. This method is, however, expensive and requires good proximity to the SEMS location to be practicable.

A combination of both MicroSD card and Cloud is usually the most preferred solution for most SEMS application, [1], [7], [27], [32], [33], [35], [40], [47], [48] all employed this approach.

\section{DISCUSSION AND FUTURE RESEARCH}

This section discusses and addresses the issues raised in the analytical questions stated in Section 3.

\section{AQ 1. What Constituent(s) is/are Common in All SEMS Designs? What Makes Up The SEMS?}

The general constituents of the SEMS are listed in Section 2. Figure 3 shows a diagrammatic representation of the various constituent components of the system. The current and voltage transducers sense the current and voltage, respectively, feed it into the central brain of the system, which is the Microcontroller Unit. The MCU processes the data received from the sensors, computes the power consumption in real-time, then takes the necessary action by sounding the buzzer if necessary. The data is transferred to the cloud through the wireless sensors connected to the internet for which both the endconsumer and service provider can access and send instructions to the SEMS. The relay connects and disconnects the power following the instruction received by the MCU from the service providers or the endconsumer. Solid state relays (SSR) are the best for this type of switching function [4].

\section{AQ 2. On Which Platforms are The SEMS Mainly} Based?

The word "Smart" in the SEMS refers to a network of connected devices equipped with digital technology that allows two-way communication between every connected end. This technology, as mentioned in Section 1 , is the internet of things (IoT). SEMS is based on the technology of IoT, consisting of control and automation protocols. The paper [49] asserted that the Internet of Things (IoT) and smart cities are two of the most popular directions the research community is actively pursuing.

\section{AQ 3. What Accounts for The Differences in The Various SEMS Designs?}

The differences in SEMS designs can be traced to the options of the specifications of the components and intended application. A Smart Energy Metering System that is to be used in a household is better off with the ACS712 current and LV 25-P voltage transducers. Meanwhile, a SEMS to be used in a production factory or heavy-duty industry requires high-rating sensors like the SCT 013-000 and FHS-40P/SP600current and ZMPT101B voltage transducers. Authors in [50] discussed the calibration of current and voltage sensors used in power measurement.

\section{AQ 4. What are The Future Directions and Open Perspectives in SEMS Designs?}

One of the major advantages of the SEMS over the conventional meter is the Smart Meter Data which is automatically recorded and saved for analytical purposes. Applying the intelligence of Data Science in the analytics of the data obtained can aid the deduction of more insights, which may bring about further improvements in the energy cycle. Furthermore, to enhance the powersaving opportunities provided by the SEMS, further improvement is integrating occupancy and light sensors into SEMS to control appliances in correspondence to human and light presence, respectively.

The best configuration for SEMS is difficult to agree on because the configuration is application-dependent.

\section{CONCLUSION}

In this paper, a comprehensive review of the constituents of the SEMS and the various designs that implemented each have been provided, following Kitchenham's Systematic Literature Review methodology [24]. The reviewed papers were collected from 4 online databases on which exclusion and inclusion criteria were applied to select the most relevant 31 papers. This literature asserts that the main technology on which the systems are based on the IoT. Building SEMS applications on this technology is critical to building a robust and functional smart grid capable of mitigating several problems associated with electricity distribution networks. This study also highlights the critical functional elements of SEMS and further research direction and open issues towards enhancement and improvement of the system. 


\section{ACKNOWLEDGMENT}

This research was funded by TETFund Research Fund Grant 2019 (TETFund/DR\&D-CE/NRF/2019).

\section{REFERENCES}

[1] C. Sookasame and W. Zhongdong, "Real time power consumption monitoring using Arduino," Int. J. Res. Scientific Innov., vol. 6, no. 1, pp. 6-12, 2019.

[2] N. V. Patil, R. S. Kanase, D. R. Bondar, and P. D. Bamane, "Intelligent energy meter with advanced billing system and electricity theft detection," 2017 Int. Conf. Data Manag. Anal. Innov., 2017, pp. 36-41.

[3] P. D. Talwar and S. B. Kulkarni, "IoT based energy meter reading," Int. J. Recent Trends Eng. Res., vol. 2, no. 6, pp. 586591, Jun. 2016.

[4] K. Jose, M. Jithin, U. K. Leneesh, C. Nijeesh, and T. Benny, "Smart energy meter," Int. J. Eng. Trends Technol., vol. 22, no. 4, pp. 179-182, Apr. 2015

[5] M. M. Rahman, M. O. Islam, M. Salakin, and Noor-E-Jannat, "Arduino and GSM based smart energy meter for advanced metering and billing system," 2nd Int. Conf. Electr. Eng. Inf. Commun. Technol., 2015.

[6] P. Järventausta et al., "Smart grid power system control in distributed generation environment," Annu. Rev. Control, vol. 34, no. 2 , pp. $277-286$, Dec. 2010 .

[7] L. I. Minchala-Avila, J. Armijos, D. Pesántez, and Y. Zhang, "Design and implementation of a smart meter with demand response capabilities," Energy Procedia, vol. 103, pp. 195-200, Dec. 2016.

[8] M. Kuzlu, M. Hasan, S. Rahman, and H. Dincer, "Design of wireless smart metering system based on MSP430 MCU and Zigbee for residential application," 20117 th Int. Conf. Elect. and Electron. Eng., 2011.

[9] P. R. Daware and S. S. Patil, "A review on intelligent automatic meter reading and e-billing system using power line communication," Int. J. Sci. Res., vol. 4, no. 4, pp. 1341-1343, 2015.

[10] J. Zheng, D. W. Gao, and L. Lin, "Smart meters in smart grid: An overview," in 2013 IEEE Green Technol. Conf., 2013, pp. 57 64.

[11] D. Norris, The Internet of Things: Do-It-Yourself at Home Projects for Arduino, Raspberry Pi, and BeagleBone. USA: McGraw-Hill Education, 2015.

[12] A. P. Hiwale, D. S. Gaikwad, A. A. Dongare, and C. Mhatre, "IoT based smart energy monitoring," Int. Res. J. Eng. Technol., vol. 5, no. 3, pp. 2522-2526, 2018.

[13] A. Tiwary, M. Mahato, M. Tripathi, M. Shrivastava, M. K Chandrol, and A. Chidar, "A comprehensive review of smart energy meters: An innovative approach," Int. J. Futur. Revolut. Comput. Sci. Commun. Eng., vol. 4, no. 4, pp. 239-243, 2018.

[14] N. C. Jaramillo, C. J. F. Cardona, and J. D. V. Henao, "Smart meters adoption: Recent advances and future trends," DYNA, vol. 81, no. 183, pp. 221-230, 2014.

[15] V. Devaliya, A. Chauhan, F. Faldu, K. Mishra, and S. Choubey, "Literature review on smart energy meter," Int. J. Innovative Res. Sci. Eng. Technol., vol. 7, no. 12, pp. 12001-12003, Dec. 2018.

[16] U. M. Patel and M. M. Modi, "A Review on smart meter system," Int. J. Innovative Res. Elect. Electron. Instrum. Control Eng., vol. 3, no. 12, pp. 70-73, Dec. 2015.

[17] B. D. Sawarkar and S. S. Golait, "A review paper on automatic meter reading and instant billing," Int. J. Adv. Res. Comput. Commun. Eng., vol. 4, no. 1, pp. 213-217, Jan. 2015.

[18] S. H. Mir, S. Ashruf, Sameena, Y. Bhat, and N. Beigh, "Review on smart electric metering system based on GSM/IoT," Asian J. Elect. Sci., vol. 8, no. 1, pp. 1-6, 2019

[19] S. Araya and N. Rakesh, "Review on design of residential IoT based smart energy meters review on design of residential IoT based smart energy meters," Int. Res. J. Eng. Technol., vol. 6, no. 7, pp. 3018-3023, Jul. 2019

[20] Y. Wang, Q. Chen, T. Hong, and C. Kang, "Review of smart meter data analytics: Applications, methodologies, and challenges," IEEE Trans. Smart Grid, vol. 10, no. 3, pp. 3125-3148, May 2019.

[21] L. Ajit and Y. Bhute, "A review on IoT based smart and multifunctional energy meter," Int. J. Innov. Res. Comput. Commun. Eng., vol 5, no. 1, pp. 874-878, Jan. 2017.

[22] R. Jain, S. Gupta, C. Mahajan, and A. Chauhan, "Research paper on IOT based smart energy meter monitoring and controlling system," Int. J. Res. Electron. Comput. Eng., vol. 7, no. 2, pp. 1600 - 1604, Jun. 2019

[23] N. C. Jaramillo, C. J. F. Cardona, and J. D. V. Henao, "Smart meters adoption: Recent advances and future trends," Dyna, vol. 81 , no. 183 , pp. 221-230, 2014

[24] B. Kitchenham, O. P. Brereton, D. Budgen, M. Turner, J. Bailey, and S. Linkman, "Systematic literature reviews in software engineering - A systematic literature review," Inf. Softw. Technol., vol. 51, no. 1, pp. 7-15, Jan. 2009.

[25] H. M. Z. Iqbal, M. Waseem, and T. Mahmood, "Automatic energy meter reading using smart energy meter," Int. Conf. Eng. Emerging Technol. 2014, 2014.

[26] P. S. Varpe, P. A. Gorakshanath, and J. P. Shankar, " IoT based energy meter with current, voltage and cost monitoring system," Sci. Technol. Develop. J., vol. 9, no. 5, May 2020.

[27] OpenGreenEnergy. "Arduino energy meter: 10 steps." https://www.instructables.com/ARDUINO-ENERGY-METER/ (accessed Aug. 28, 2021)

[28] N. Javed, M. A. Shafi, N. Khan, and M. Khan, "Design of a smart energy meter with overload trip facilities," Int. J. Eng. Adv. Technol., vol. 6, no. 6, pp. 107-117, Aug. 2017.

[29] F. K. Handhal and A. T. Rashid, "A prototype design for threephase smart energy meter," 2017 2nd Al-Sadiq Int. Conf. Multidiscip. IT Commun. Sci. Appl., 2017, pp. 262-267.

[30] T. M. Chung and H. Daniyal, "Arduino based power meter using instantaneous power calculation method," Asian Res. Publishing Netw. J. Eng. Appl. Sci., vol. 10, no. 21, pp. 9791-9795, Nov. 2015.

[31] E. Kabalci and Y. Kabalci, Energy Systems in Electrical Engineering Smart Grids and Their Communication Systems, 1st ed. US: Springer, 2019

[32] C. Mcnally, "Arduino based wireless power meter," M.S. thesis, Cornell Univ., 2010.

[33] N. David, F. N. Anozie, F. O. Ebuka, and S. A. Nzenweaku, "Design of an Arduino based wireless," Int. J. Sci. Eng. Res., vol. 7, no. 9, pp. 466-469, Sep. 2016

[34] F. Sanchez-Sutil, A. Cano-Ortega, J. C. Hernandez, and C. RusCasas, "Development and calibration of an open-source, low-cost power smart meter prototype for PV household-prosumers," Electron., vol. 8, no. 8, pp. 33-37, Aug. 2019, Art. no.878.

[35] S. Utami, Faridah, N. A. Azizi, E. Kencanawati, M. A. Tanjung, and B. Achmad, "Energy monitoring system for existing buildings in indonesia," E3S Web Conf., vol. 42, 2018, Art. no. 01003.

[36] Freescale Semiconductor, Appl. Note AN4164, pp. 1-7.

[37] S. S. Wagh and S. P. Kharde, "Review on design and implementation of intelligent energy meter using Arduino and GSM modem," Int. J. Innov. Res. Sci. Eng. Technol., vol. 6, no. 11, pp. 21384-21388, Nov. 2017.

[38] R. Jain. "IoT based electricity energy meter using ESP12 and Arduino." Circuitdigest.Com. [Online]. Available: https://circuitdigest.com/microcontroller-projects/iot-electricityenergy-meter-using-esp12-arduino

[39] U. A. Takte and A. V. Nikalje, "An embedded electric meter using ARM, ZigBee and GSM," Int. J. Innov. Res. Comput. Commun. Eng., vol. 4, no. 6, pp.12415-12419, Jun. 2016.

[40] S. K. Pal, A. Ranjan, A. Mishra, C. P. Singh, and A. Srivastava, "Electric meter reading through IoT by using Raspberry pi model," Int. Res. J. Eng. Technol., vol. 5, no. 3, pp. 3603-3608, Mar. 2018.

[41] S. Jain et al., "Smart energy metering using LPWAN IoT technology," India Smart Grid Week 2017: Compendium of Technical Papers, 2018, pp. 19-28.

[42] B. K. Sahani, T. Ravi, A. J. Tamboli, and R. Pisal, "IoT based smart energy meter," Int. Res. J. Eng. Technol., vol. 4, no. 4, pp. 96-102, Apr. 2017.

[43] A. Raj. "Arduino wattmeter: Measure voltage, current and power consumption." [Online]. Available: https://circuitdigest.com/microcontroller-projects/arduinowattmeter-to-measure-voltage-current-power-consumption

[44] N. H. Mustafa, M. N. Husain, M. A. A. Aziz, M. A. Othman, and F. Malek, "Development of energy monitoring system based on human behavior by using Arduino microcontroller," in 8th Malaysia University Conf. Engineering Technology, 2014

[45] K. Govinda, "Design of smart meter using Atmel 89S52 microcontroller," Procedia Technol., vol. 21, pp. 376-380, 2015.

[46] S. Karnouskos, O. Terzidis, and P. Karnouskos, "An advanced metering infrastructure for future energy networks.," in New 
Technologies, Mobility and Security. Springer, Dordrech, 2007, ch. 49 , pp. 597-606.

[47] N. V. Patil, R. S. Kanase, D. R. Bondar, and P. D. Bamane, "Intelligent energy meter with advanced billing system and electricity theft detection," in 2017 Int. Conf. Data Management, Analytics and Innovation, 2017, pp. 36-41.

[48] C. Klemenjak, D. Egarter, and W. Elmenreich, "YoMo: the Arduino-based smart metering board," Comput. Sci. - Res. Dev. vol. 31, no. 1-2, pp. 97-103, 2016.
[49] G. Mylonas, D. Amaxilatis, S. Tsampas, L. Pocero, and J. Gunneriusson, "A methodology for saving energy in educational buildings using an IoT infrastructure," 10th Int. Conf. Information, Intell. Syst. Appl., 2019.

[50] P. M. Ramos, N. B. Bras, and A. C. Serra, "A new calibration method for current and voltage sensors used in power quality measurements," 2006 IEEE Instrumentation and Measurement Technology Conf. Proc., 2007, pp. 2283-2288. 